\title{
Application of numerical simulations for a tentative seismic microzonation of the city of Rome
}

\author{
Donat Fäh $\left({ }^{1}\right)(*)$, Claudio Iodice $\left({ }^{1}\right)$, Peter Suhadolc $\left({ }^{1}\right)$ and Giuliano F. Panza $\left({ }^{1}\right)\left({ }^{2}\right)$ \\ (1) Istituto di Geodesia e Geofisica, Università degli Studi di Trieste, Italy \\ (2) International Center for Theoretical Physics, Trieste, Italy
}

\begin{abstract}
A hybrid technique, based on mode summation and finite differences, was used to simulate the ground motion induced in the city of Rome by possible earthquakes occurring in the main seismogenetic areas surrounding the city: the Central Apennines and the Alban Hills. The results of the numerical simulations are used for a seismic microzonation in the city of Rome, which can be used for the retrofitting of buildings of special social and cultural value. On the basis of our analysis Rome can be divided into six main zones: (1) the edges and (2) basin; the areas of the alluvial basin of the River Tiber; (3) the edges and (4) the central part of the Paleotiber without and (6) areas the large basins of the Tiber and Paleotiber, where we distinguish between (5) areas have to be expected at the lo surface. The strongest amplification effects have to be expected at the edges of the Tiber basin, with maximum spectral amplification of the order of 5 to 6 , and strong amplifications occur inside the entire alluvial basin of the Tiber. The presence of a near-surface layer of rigid material is not sufficient to classify a location as a «hard-rock site», when the rigid material covsurface due to resonance effects. This is that the underlying sedimentary complex causes amplifications at the plifications in the frequency range $0.4-1.0 \mathrm{~Hz}$ reach values of the order of 3 to 4 .
\end{abstract}

Key words Rome - wave-propagation modelling seismic strong ground motion - seismic microzonation

\section{Introduction}

Numerical simulations play an important role in the estimation of strong ground motion. They can provide synthetic signals for areas where recordings are absent and are, therefore, very useful for engineering design of earthquake-resistant structures and for the ret-

(*) Now at: Institut für Geophysik, ETH-Hönggerberg, CH-8093 Zürich, Switzerland. rofitting of particularly important buildings. Lateral heterogeneities and sloping layers, commonly present in nature, can cause effects that dominate the ground motion: the excitation of local surface-waves, focusing and defocusing of waves, and resonance effects. In such circumstances, at least two-dimensional techniques are necessary for a realistic estimate of the ground motion.

To include both a realistic source model and a complex structural model of the site of interest, a hybrid method has been developed that combines modal summation and the finite difference technique (Fäh, 1992; Fäh et al., 1993, 1994). The propagation of the waves from the source up to the local structure at the site is computed with the mode-summation method for plane layered anelastic structures (Panza, 
1985; Florsch et al., 1991). The mode-summation method allows the simulation of the complete incident wavefield in given phase-velocity and frequency bands. Explicit finite-difference schemes (Korn and Stöckl, 1982; Virieux, 1986) are then used to simulate the propagation of seismic waves in a two-dimensional model of the local structure. The hybrid method is particularly suitable to compute the ground motion in two-dimensional models of any complexity, and allows us to take into account the source and propagation effects, including local site conditions.

The area of Rome, considered here, is characterized by several sedimentary basins of considerable thickness, which in some parts are covered by volcanic rocks. The area is very vulnerable to earthquakes, as indicated, for example, by the well-documented damage distribution caused by the $M_{L}=6.8$ January 13 , 1915, Fucino (Italy) earthquake (Ambrosini et al., 1986). In the absence of instrumental data in the city of Rome, a numerical simulation of the ground motion due to the January 13, 1915 Fucino earthquake was compared with the observed damage distribution (Fäh et al., 1993). The macroseismic data in Rome shows essentially that the damage is concentrated at the edges of the alluvial basin of the Tiber River; the heavy and intermediate damage are located in that basin. The same distribution of damage can be expected on the basis of the numerical simulations of this event (Fäh et al., 1993). The highest amplifications are observed at the edges of this alluvial basin, and large amplifications can be observed within the Tiber's River bed. The very good correlation between the damage statistics and the ground motion suggests using the hybrid technique for a microzonation of the entire town, which accounts also for events expected in other important seismogenetic areas. For this purpose, a series of different numerical simulations of the ground motion were performed, for different source positions and structural models of the Rome area. The results of such computations were then used for microzonation, based on the spectral amplifications expected in the different zones of the city.

\section{Parametrization of the source and the propagation path}

The most important seismogenetic zones (fig. 1) which can produce structural damage in Rome are the Central Apennines, whose earthquakes can cause, in the town, an observed maximum intensity VII-VIII on the MercalliCancani-Sieberg intensity scale (MCS), and the Alban Hills, whose earthquakes are responsible for an observed maximum MCS intensity in Rome equal to VI-VII (Molin et al., 1986). The source positions (fig. 1) used in this study include (1) the epicenter of the January 13, 1915 Fucino earthquake, (2) an epicenter close to the Carseolani Mountains where, from a study of pattern recognition (Caputo et al., 1980), a strong earthquake is expected to occur, and (3) the Alban Hills. The source mechanisms assigned to these earthquakes are the mechanism of the Fucino earthquake (Gasparini et al., 1985) for events 1 and 2, and the mechanism of a recent earthquake in the Alban Hills (Amato et al., 1984) for event 3. The pa-

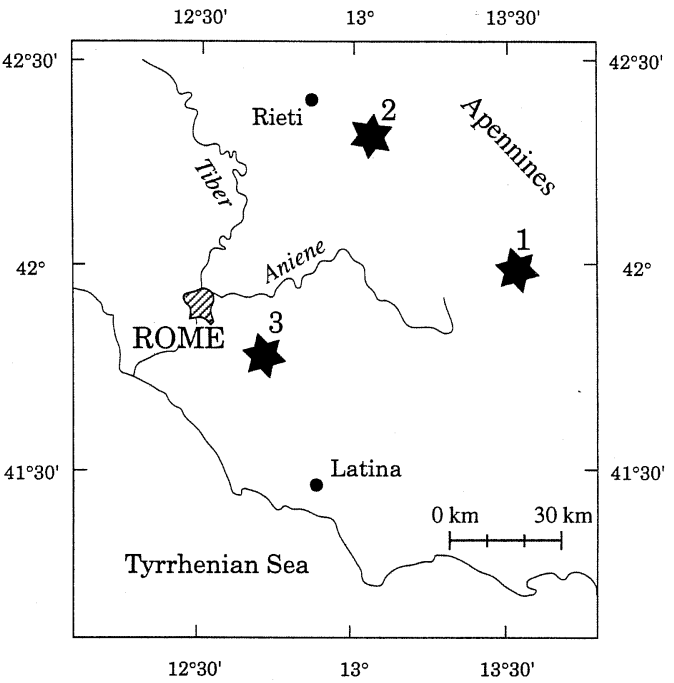

Fig. 1. Epicenter locations of the events used for the different numerical simulations. The source positions are (1) the epicenter of the January 13, 1915 Fucino earthquake, (2) an epicentre close to the Carseolani Mountains, and (3) the Alban Hills. 
Table I. Source mechanisms of the events shown in fig. 1.

\begin{tabular}{clcccc}
\hline \hline $\begin{array}{c}\text { Event } \\
\text { No. }\end{array}$ & \multicolumn{1}{c}{ Location } & $\begin{array}{c}\text { Source } \\
\text { depth }(\mathrm{km})\end{array}$ & Dip & Rake & $\begin{array}{c}\text { Strike-receiver } \\
\text { angle }\end{array}$ \\
\hline 1 & Fucino valley & 8.00 & $39^{\circ}$ & $172^{\circ}$ & $38^{\circ}$ \\
2 & Carseolani Mountains & 8.00 & $39^{\circ}$ & $172^{\circ}$ & $38^{\circ}$ \\
3 & Alban Hills & 3.06 & $74^{\circ}$ & $266^{\circ}$ & $133^{\circ}$ \\
\hline
\end{tabular}

rameters of the focal mechanism of each event are given in table I.

The one-dimensional structural models for the region between the source positions and Rome are given in table II. The $P$-wave velocities in the crust are based on seismic refraction measurements made along the profile LatinaPescara (Nicolich, 1981). The shear-wave velocities were chosen by assuming that $v_{S}^{2}=v_{P}^{2} / 3$. The Moho depth $(28 \mathrm{~km})$ is in good agreement with other published results (Nicolich, 1989; Suhadolc and Panza, 1989). These models were used as reference bedrock structures, and, for each seismic source, the ground motion computed with the hybrid method was always compared with that obtained for the related one-dimensional structure.

The position of the cross sections studied is shown in fig. 2, and the related two-dimensional structural models are shown in fig. 3 . They are based on all the available geological and geotechnical information (Ventriglia, 1971; Serva et al., 1986; Funiciello et al., 1987; Boschi et al., 1989; Feroci et al., 1990). Alluvial sediments can be found in two major areas, the river beds of the Aniene and Tiber. The ancient river bed of the Tiber (referred as Paleotiber) is composed of Sicilian clays, sands and gravel. This sedimentary complex is covered by volcanic rocks which have their origin in the Pleistocene volcanic activity (Ventriglia, 1971). The volcanic rocks have greater wave velocities than the underlying sediments (Sicilian) which, therefore, define a buried lowvelocity zone. The surficial layer consists of compacted fill, and of the foundations of manmade structures. The transition from the alluvial sediments in the Tiber River bed to the compacted clay is characterized by a very high impedance contrast. In fig. 3, the compacted clay is referred to as bedrock, and its material properties are related to the values given in table II. The velocity gradient in the uppermost part of the structure for the bedrock is approximated by a series of thin layers.

Since the mechanical properties and thickness of the different soils are not well known, we have used different material properties to test the stability of the microzonation and enhance its reliability. Our tests include: (1) two different models for which the seismic phase velocities given in fig. 3 are defined at $1 \mathrm{~Hz}$ and at $30 \mathrm{~Hz}$, respectively, while the $Q$-values are not varied, and (2) two different models in which the surficial layer of man-made ground (fill deposits) has a thickness of $5 \mathrm{~m}$ and $10 \mathrm{~m}$, respectively.

\section{Properties of the ground motion caused by the Fucino event}

Several ground motion related quantities can be extracted from the synthetic accelerograms obtained from our numerical modelling. The quantities that we consider here are: (1) the relative peak ground acceleration PGA(2D)/PGA(bedrock), (2) the so-called relative Arias intensity $W(2 \mathrm{D}) / W$ (bedrock) (Arias, 1970), where $W$ is defined as:

$$
W=\frac{\pi}{2 g} \lim _{t \rightarrow \infty} \int_{0}^{t}[\ddot{x}(\tau)]^{2} d \tau,
$$

where $x$ is the ground displacement, and (3) the relative spectral accelerations or spectral amplification $S a(2 \mathrm{D}) / S a$ (bedrock), where $S a$ is the spectral acceleration. PGA(2D), $W(2 \mathrm{D})$, 
Table II. Structural bedrock models representative of the path from the epicenters to the city of Rome $\left(Q_{\alpha}=2.2 Q_{\beta}\right)$. For the computations with source 3, located in the Alban Hills, the mechanical parameters of the first layer are given in parenthesis. The velocity gradients in the models are approximated by a series of thin layers.

\begin{tabular}{|c|c|c|c|c|}
\hline $\begin{array}{l}\text { Thickness } \\
(\mathrm{km})\end{array}$ & $\begin{array}{l}\text { Density } \\
\left(\mathrm{g} / \mathrm{cm}^{3}\right)\end{array}$ & $\begin{array}{c}P \text {-wave } \\
\text { velocity }(\mathrm{km} / \mathrm{s})\end{array}$ & $\begin{array}{c}S \text {-wave } \\
\text { velocity }(\mathrm{km} / \mathrm{s})\end{array}$ & $Q_{\beta}$ \\
\hline 0.09 & $2.24(2.21)$ & $2.40(1.85)$ & $1.29(1.00)$ & $30(20)$ \\
\hline 0.10 & 2.25 & 2.50 & 1.30 & 30 \\
\hline 0.10 & 2.25 & 2.80 & 1.50 & 30 \\
\hline 0.10 & 2.30 & 4.00 & 2.31 & 100 \\
\hline 0.10 & 2.40 & 4.10 & 2.37 & 100 \\
\hline 0.10 & 2.40 & 4.20 & 2.43 & 100 \\
\hline 0.10 & 2.50 & 4.30 & 2.48 & 100 \\
\hline 0.10 & 2.50 & 4.40 & 2.54 & 100 \\
\hline 0.10 & 2.50 & 4.50 & 2.60 & 100 \\
\hline 0.10 & 2.50 & 4.60 & 2.65 & 100 \\
\hline 0.10 & 2.60 & 4.70 & 2.70 & 100 \\
\hline 0.10 & 2.60 & 4.80 & 2.77 & 100 \\
\hline 0.10 & 2.60 & 4.90 & 2.83 & 100 \\
\hline 0.10 & 2.60 & 5.00 & 2.88 & 100 \\
\hline 0.10 & 2.60 & 5.20 & 3.00 & 100 \\
\hline 0.10 & 2.60 & 5.40 & 3.10 & 100 \\
\hline 0.10 & 2.60 & 5.60 & 3.20 & 100 \\
\hline 1.70 & 2.80 & 5.70 & 3.30 & 100 \\
\hline 6.10 & 2.85 & 6.00 & 3.46 & 100 \\
\hline 0.10 & 2.85 & 5.89 & 3.40 & 100 \\
\hline 0.10 & 2.85 & 5.80 & 3.35 & 100 \\
\hline 0.10 & 2.85 & 5.71 & 3.30 & 100 \\
\hline 0.10 & 2.85 & 5.54 & 3.20 & 100 \\
\hline 8.60 & 2.85 & 5.40 & 3.12 & 100 \\
\hline 0.10 & 2.85 & 5.49 & 3.17 & 100 \\
\hline 0.10 & 2.85 & 5.63 & 3.25 & 100 \\
\hline 0.10 & 2.85 & 5.71 & 3.30 & 100 \\
\hline 0.10 & 2.85 & 5.89 & 3.40 & 100 \\
\hline 0.10 & 2.85 & 6.06 & 3.50 & 100 \\
\hline 2.70 & 2.85 & 6.20 & 3.58 & 300 \\
\hline 1.70 & 2.88 & 6.50 & 3.75 & 300 \\
\hline 1.70 & 2.90 & 6.70 & 3.87 & 300 \\
\hline 2.40 & 2.95 & 7.00 & 4.04 & 300 \\
\hline 4.75 & 3.35 & 7.90 & 4.56 & 300 \\
\hline 4.75 & 3.35 & 7.92 & 4.57 & 300 \\
\hline 4.75 & 3.35 & 7.94 & 4.58 & 300 \\
\hline 4.75 & 3.35 & 7.96 & 4.59 & 300 \\
\hline 4.75 & 3.35 & 7.98 & 4.60 & 300 \\
\hline 4.75 & 3.35 & 8.00 & 4.62 & 300 \\
\hline 4.75 & 3.36 & 8.02 & 4.63 & 300 \\
\hline 4.75 & 3.37 & 8.04 & 4.64 & 300 \\
\hline 4.75 & 3.38 & 8.06 & 4.65 & 300 \\
\hline$\infty$ & 3.39 & 8.08 & 4.66 & 300 \\
\hline
\end{tabular}


Thicknesss of the alluvial sediments
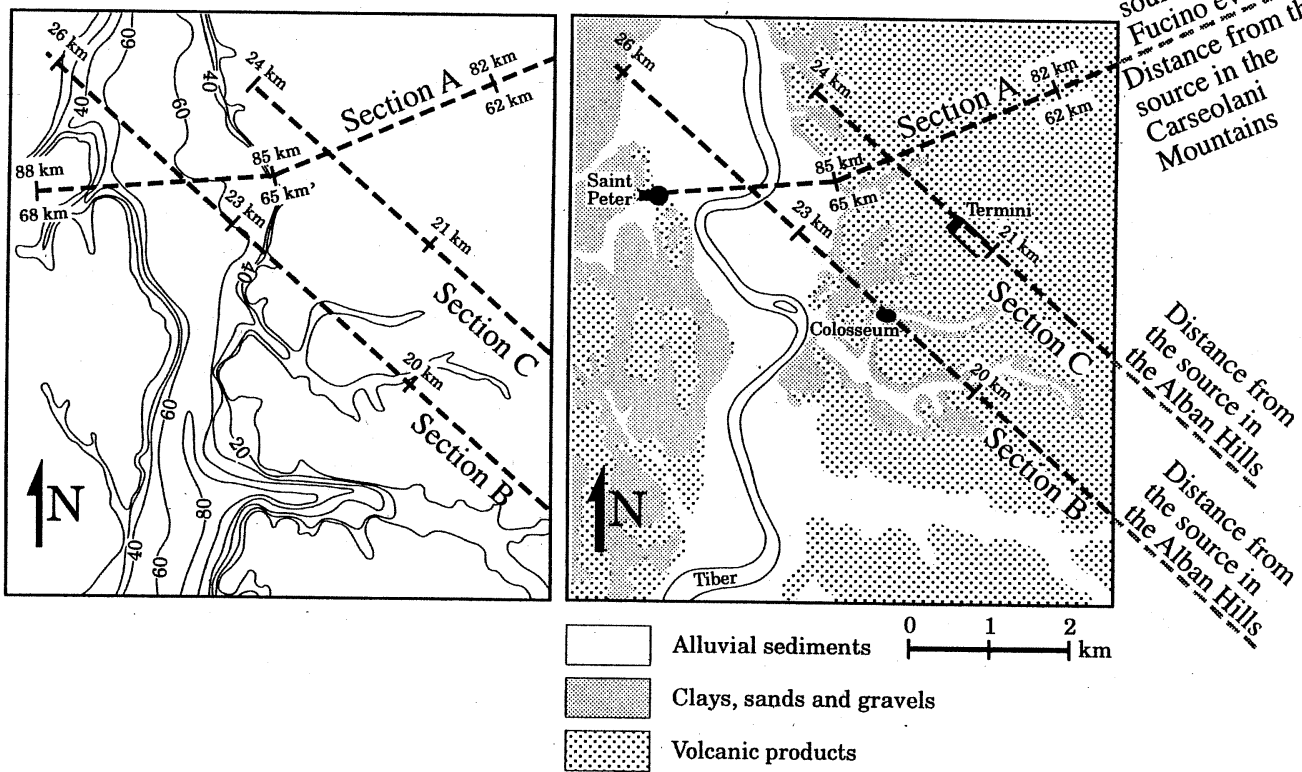

Clays, sands and gravels

Volcanic products

Fig. 2. Lithology and thickness of alluvial sediments in Rome (Ventriglia, 1971; Funiciello et al., 1987; Feroci et al., 1990). The dashed lines indicate the positions of the cross sections, for which numerical modelling is performed.

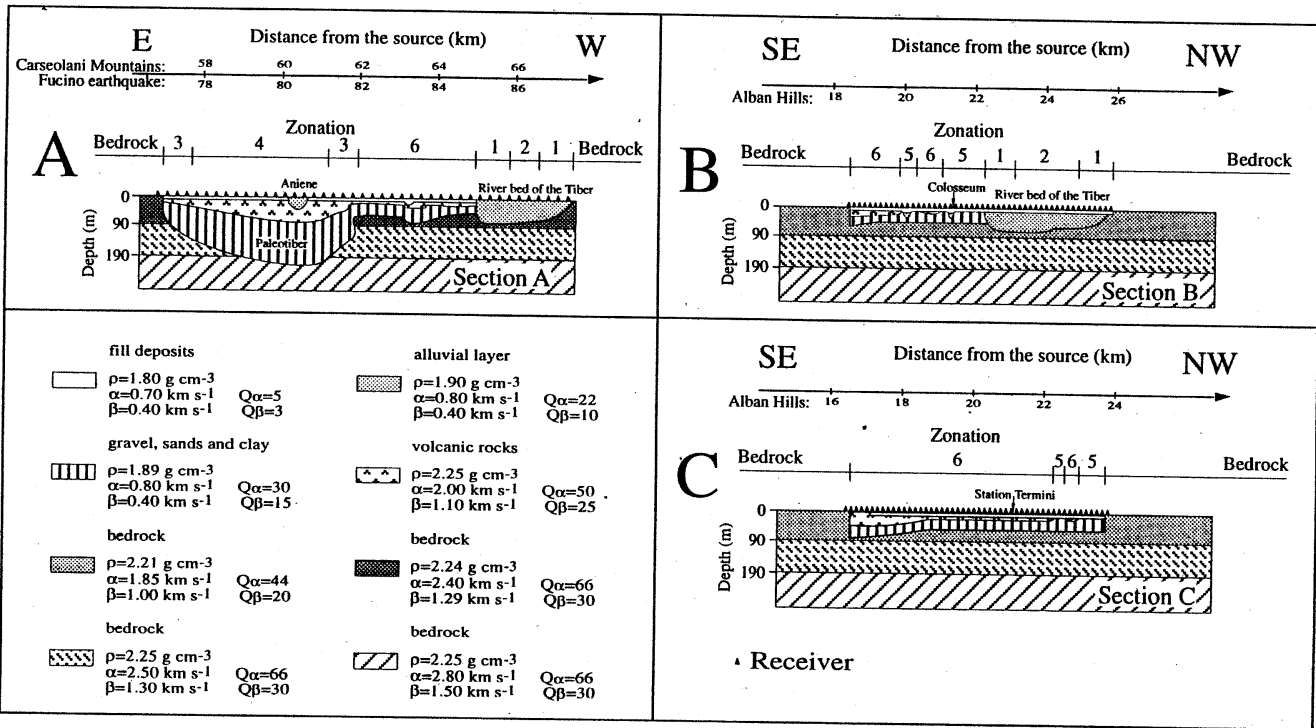

Fig. 3. Two-dimensional models corresponding to the dashed lines shown in fig. 2. Only the part near to the surface is shown, where the 2D model deviates from the horizontally-layered structural models shown in table II. The general microzonation is explained in the text. 


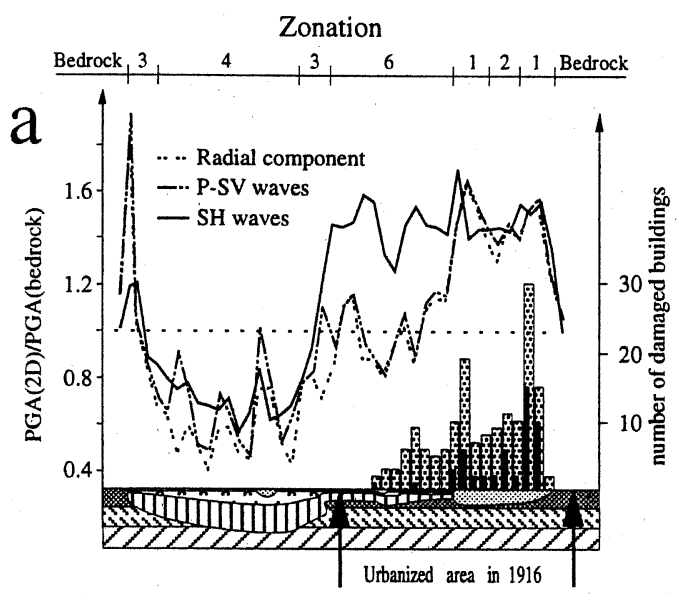

order to remove the effects of the regional propagation, PGA(2D), $W(2 \mathrm{D})$, and $S a(2 \mathrm{D})$ are always normalized with respect to the related quantities PGA(bedrock), $W$ (bedrock), $S a$ (bedrock), computed in the reference bedrock model for the same seismic source and the same source-receiver distance.

For the Fucino event (event 1), relative PGA and relative Arias intensity, defined by the ratios PGA(2D)/PGA(bedrock) and $W(2 \mathrm{D}) / W$ (bedrock), computed for the transverse component of motion ( $\mathrm{SH}$-waves), the radial component of motion, and the total $P-S V$ wavefield (radial and vertical component of motion), are shown in fig. 4. High relative PGA values are observed for locations sitting on unconsolidated sediments (fig. 4a), while relative PGA values are low where the volcanic layer is thick. Relative peaks can be seen at the beginning of the alluvial valley of the Tiber and within the alluvial valley of the Aniene. The peaks and troughs are more evident in the curve representing the relative $W$ values (fig. 4b). There are five relative peaks: two at the edges of the Tiber basin, one within the alluvial valley of the Aniene, a broad peak where the Sicilian low-velocity zone is close to the surface, and one at the margin of the Paleotiber basin.

The macroseismic data show essentially that, in Rome, the damage is concentrated in the basin of the Tiber with clear peaks at the edges of the alluvial basin. To quantify this observation, the damage distribution has been projected on the cross section used in the numerical modelling (Fäh et al., 1993). The resulting histogram is shown in fig. 4 , which shows that a similar distribution of damage is predicted by our direct numerical simulation. They are compared with the damage distribution caused by the January 13, 1915 Fucino earthquake (Fäh et al., 1993). The general microzonation is explained in the text.

$S a(2 \mathrm{D})$ indicate, respectively, PGA, $W$ and $S a$ computed for the two-dimensional models shown in fig. 3. PGA(bedrock), W(bedrock), and $S a$ (bedrock) indicate, respectively, PGA, $W$ and $S a$ obtained for the one-dimensional reference bedrock models given in table II. In

\section{Seismic microzonation}

The results obtained from the modelling of the Fucino event (fig. 4) can be used directly for general microzonation purposes. Using as reference the bedrock models given in table II, six zones can be distinguished (see figs. 3 and 4): (1) zone 1 includes the edges of the Tiber River, (2) zone 2 extends over the central part 
of the alluvial basin of the Tiber, (3) zone 3 includes the edges of the Paleotiber basin, and (4) zone 4 extends over the central part of the Paleotiber basin. Zones 5 and 6 include areas which are located outside the large basins of the Tiber and Paleotiber where we distinguish between areas (5) without and (6) with a layer of volcanic rocks close to the surface. Due to analogous geological conditions, these zones can be recognized in the sections considered in relation with the events located in the Carseolani Mountains and the Alban Hills, as is shown in fig. 3 .

For all the receivers of all two-dimensional models and studied events, we have computed the spectral amplification $S a(2 \mathrm{D}) / \mathrm{Sa}$ (bedrock) for one hundred frequencies of the oscillator, in the frequency range 0.2 to $4 \mathrm{~Hz}$. For a certain zone, we have computed the average of all spectral amplification curves obtained for the receivers in this zone. Moreover, we have determined the maximum spectral amplification observed for all receivers in this zone. The results obtained for zero damping and 5\% damping of the oscillator are shown in fig. 5. With respect to bedrock, the maximum spectral amplification defines the maximum amplification effects to be expected in a certain zone. The average spectral amplification defines amplification and attenuation effects which are similar for all receivers in a certain zone, and the difference between the maximum and average spectral amplification is a measure for the variability of the ground motion in a zone.

The greatest spectral amplification is observed at the edges of the sedimentary basin of the Tiber River (zone 1), for frequencies between 2.0 and $2.5 \mathrm{~Hz}$. The maximum spectral
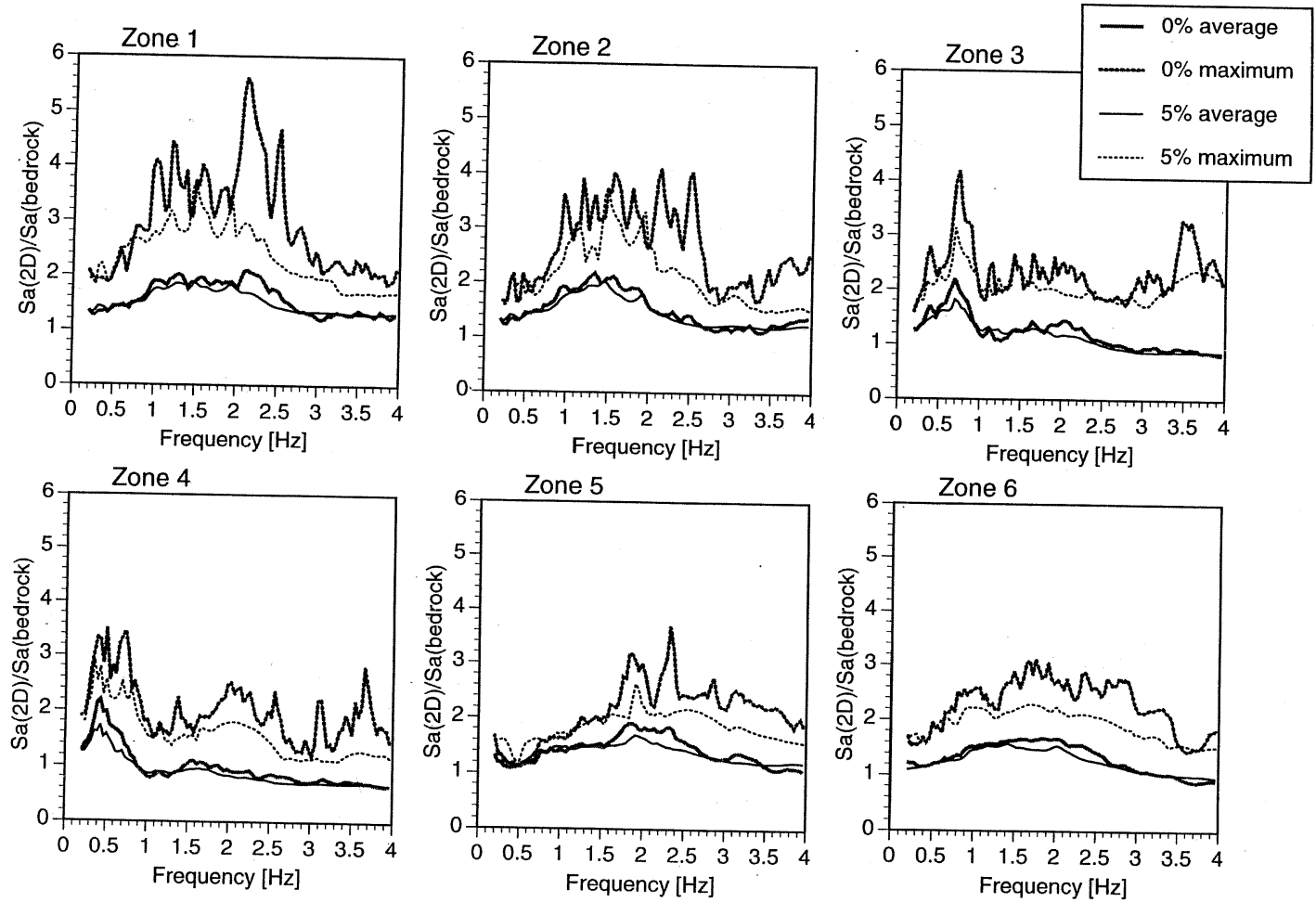

Fig. 5. Maximum and average spectral amplifications for the zones defined in figs. 3 and 4 , for zero damping
and $5 \%$ damping. 
amplification with respect to the bedrock model varies between 5 and 6 , and it is due to the combination of resonance effects with the excitation of local surface waves (Fäh et al., 1993). The general shape of the maximum and average spectral amplifications are similar for zones 1 and 2. In the frequency range from $1.0 \mathrm{~Hz}$ to $3.0 \mathrm{~Hz}$, the maximum spectral amplification is of the order of 4 and the average spectral amplification is of the order of 2 .

Similar observations can be made for the Paleotiber basin (zones 3 and 4), but in a different frequency band $(0.4-1.0 \mathrm{~Hz})$. The buried sedimentary complex (Sicilian) causes maximum spectral amplification between 3 and 4, due to resonance effects. These are most pronounced at frequencies around $0.6 \mathrm{~Hz}$. Therefore, the presence of a near-surface layer of rigid material in the Paleotiber basin is not sufficient to classify that area as a «hard-rock site». A correct zonation requires the knowledge of both the thickness of the surficial layer and of the deeper parts of the structure, down to the real bedrock. This is especially important in volcanic areas, where pyroclastic material often covers alluvial basins. The maximum spectral amplification is larger at the edges of the Paleotiber basin (zone 3). For frequencies above $1.0 \mathrm{~Hz}$, in the Paleotiber basin (zone 4), the volcanic layer acts as a shield reflecting part of the incoming energy, and the values of the average spectral amplification are smaller than 1 .

For the sites in zones 5 and 6 , the maximum and the average spectral amplifications are small for frequencies below $1 \mathrm{~Hz}$. Since the sedimentary cover in these zones is thin, the amplification takes place at frequencies above $1.5 \mathrm{~Hz}$, and changes rapidly from site to site. This rapid variation leads to average values of the order of 1.0-1.5.

\section{Summary and conclusions}

In the absence of instrumental data, realistic numerical simulations of the ground motion, successfully tested against macroseismic data, are used for the microzonation of Rome. The zonation is based on the numerical simulation of wave propagation along different profiles, by taking into account realistic seismic sources, the propagation paths of the seismic waves, and the uncertainty of material properties. The results of such computations are used to define the spectral amplifications expected in different zones of the city. Using as reference a bedrock model, six main zones can be distinguished, each one characterized by specific geological conditions. This characterization allows us to extend the results to sites in the Rome area which are not located on the cross-sections studied, but which have similar geological conditions as those defined in our modelling.

In general, for sites close to lateral heterogeneities, the amplification effects are maximum. The highest values of the spectral amplification (between 5 and 6), are observed at the edges of the sedimentary basin of the Tiber, and strong amplifications are observed in the Tiber's River bed. This is caused by the large amplitudes and long duration of the ground motion due to (1) the low impedance of the alluvial sediments, (2) resonance effects, and (3) the excitation of local surface waves. Similar observations can be made for the Paleotiber basin, where the buried sedimentary complex causes the maximum spectral amplification between 3 and 4, which can be explained by resonance effects.

Our technique can be applied routinely in microzonation studies, and it provides realistic estimates of amplification and attenuation effects for two-dimensional, anelastic models. Since geotechnical data are available for many areas, the proposed technique provides a scientifically and economically valid procedure for the immediate (no need to wait for a strong earthquake to occur) seismic microzonation of any urban area, and it can be very useful for the engineering design of earthquake-resistant structures and for the retrofitting of particularly important buildings.

\section{Acknowledgements}

We would like to thank ENEA for allowing us the use of the IBM3090E computer at the ENEA INFO BO Computer Center. D.F. has been supported by the Swiss National Science 
Foundation under Grant No. 8220-037189. This study has been made possible by the contracts CNR 91.02692.CT15, CNR 92.00068. CT12, CNR 92.02422.CT15, CNR 92.02867. PF54, and EEC EPOC-CT91-0042, and by MURST $(40 \%$ and $60 \%$ ) funds. This research has been carried out in the framework of the ILP Task Group II.4 contributions to the IDNDR project «Physical Instability of Megacities».

\section{REFERENCES}

Amato, A., B. De Simoni and C. Gasparini (1984): Considerazioni sulla sismicità dei Colli Albani, in Atti del $3^{\circ}$ Convegno del Gruppo Nazionale di Geofisica della Terra Solida, CNR, Roma, vol. 2, 965-976.

Ambrosini, S., S. Castenetto, F. Cevolani, E. Di LORETO, R. Funiciello, L. LiPERI and D. Molin (1986): Risposta sismica dell'area urbana di Roma in occasione del terremoto del Fucino del 13 gennaio 1915, Risultati preliminari, Mem. Soc. Geol. It., 35, 445-452.

ARIAS, A. (1970): A measure of earthquake intensity, in Seismic Design for Nuclear Power Plants, edited by R. HANSEN (Cambridge, Mass.), 438-483.

Boschi, E., M. Feroci, R. Funiciello, L. Malagnini, A. Rovelli and S. SAlvi (1989): Valutazione della risposta sismica in ambiente urbano: risultati per la città di Roma, in Atti dell' $8^{\circ}$ Convegno Gruppo Nazionale Geofisica della Terra Solida, CNR, Roma, 317-326.

Caputo, M., V. Keilis-Borok, E. Oficerova, E. RanZMAN, I. Rotwain and A. SolovjefF (1980): Pattern recognition of earthquake-prone areas in Italy, Phys. Earth. Planet. Int., 21, 305-320.

FÄH, D. (1992): A hybrid technique for the estimation of strong ground motion in sedimentary basins, $P h$. D. Thesis No. 9767, Swiss Federal Institute of Technology, Zurich.

FÄH, D., C. IOdice, P. SuHAdolc and G.F. PANZA (1993): A new method for the realistic estimation of seismic ground motion in megacities: the case of Rome, Earthquake Spectra, 9 (4), 643-668.

FÄH, D., P. Suhadolc, ST. Mueller and G.F. Panza (1994): A hybrid method for the estimation of ground motion in sedimentary basins; quantitative model- ling for Mexico City, Bull. Seismol. Soc. Am., 84, 383-399.

Feroci, M., R. Funiciello, F. Marra and S. Salvi (1990): Evoluzione tettonica e paleogeografica pliopleistocenica dell'area di Roma, Il Quaternario, 3, $141-158$

Florsch, N., D. FÄH, P. Suhadolc and G.F. PANZA (1991): Complete synthetic seismograms for highfrequency multimode $S H$-waves, $P A G E O P H$, 136, 529-560.

Funiciello, R., G. LORIA and S. SALVI (1987): Ricostruzione delle superfici strutturali del sottosuolo della città di Roma, in Atti del $6^{\circ}$ Convegno Gruppo Nazionale Geofisica della Terra Solida, CNR, Roma, 395-415.

Gasparini, C., G. IAnNaccone and R. Scarpa (1985): Fault-plane solutions and seismicity of the Italian peninsula, Tectonophysics, 117, 59-78.

KORN, M. and H. STÖCKL (1982): Reflection and transmission of Love channel waves at coal seam discontinuities computed with a finite difference method, J. Geophys., 50, 171-176.

Molin, D., S. Ambrosini, S. Castenetto, E. Di Loreto, L. LIPERI and A. PACIELLO (1986): Aspetti della sismicità storica di Roma, Mem. Soc. Geol. It., 35, 439-444.

NicOLICH, R. (1981): Il profilo Latina-Pescara e le registrazioni mediante OBS nel Mar Tirreno, in Atti del $1^{\circ}$ Convegno Gruppo Nazionale Geofisica della Terra Solida, CNR, Roma, 621-637.

NICOLICH, R. (1989): Crustal structures from seismic studies in the frame of the European Geotraverse (Southern Segment) and CROP projects, in The Lithosphere in Italy: Advances in Earth Science Research, Atti dei Convegni Lincei, 80, 41-61.

PANZA, G.F. (1985): Synthetic seismograms: the Rayleigh waves modal summation, J. Geophys., 58, 125-145.

Serva, L., A.M. Blumetti and A.M. MichetTi (1986): Gli effetti sul terreno del terremoto del Fucino (13 gennaio 1915); tentativo di interpretazione della evoluzione tettonica recente di alcune strutture, $\mathrm{Mem}$. Soc. Geol. It., 35, 893-907.

Suhadolc, P. and G.F. PANZA (1989): Physical properties of the lithosphere-asthenosphere system in Europe from Geophysical Data, in The Lithosphere in Italy: Advances in Earth Science Research, Atti dei Convegni Lincei, 80, 15-40.

Ventriglia, U. (1971): La geologia della città di Roma, Amm. Prov. di Roma, Roma.

VIRIEUX, J. (1986): $P-S V$ wave propagation in heterogeneous media: velocity-stress finite-difference method, Geophysics, 51, 889-901. 